\title{
Mallory bodies in alcoholic and non-alcoholic liver disease contain a common antigenic determinant
}

\author{
K A Fleming, J A MORTON, C BARBATIS, J BURNS, S CANNing, \\ AND J O'D MCGEE* \\ From the University of Oxford, Nuffield Department of Pathology, John Radcliffe Hospital, Oxford
}

SUMMARY An immunohistochemical technique is described for the detection of Mallory bodies (MBs) in paraffin sections of liver tissue. This is based on proteolytic digestion of sections before exposure to an antiserum which recognises a unique antigenic determinant in MBs. With the use of this procedure it has been shown in alcoholic liver disease, primary biliary cirrhosis, Indian childhood cirrhosis, Wilson's disease, diabetes mellitus, and hepatocellular cancer that the MBs found in these disorders contain this unique antigenic determinant. It is postulated, therefore, that the mechanism of formation of MBs is similar in liver diseases of diverse aetiology. In addition, it has been demonstrated that the immunohistochemical procedure is more sensitive than routine staining; MBs were detected in five out of 12 fatty livers by immunohistochemistry and only in one by $\mathrm{H}$ and $\mathrm{E}$ staining. As $\mathrm{MBs}$ in fatty livers were not associated with polymorph infiltration or fibrogenesis it is argued that MB formation is not an absolute prerequisite for the progression of acute to chronic liver disease.

As it is known that not all heavy drinkers of alcohol (10-30\%), ultimately develop cirrhosis, ${ }^{1}$ a major problem in alcoholic liver disease is predicting which heavy drinkers will progress to cirrhosis. In baboons, fed alcohol over a prolonged period, it has been suggested that the development of pericentral venous fibrosis determines the progression to cirrhosis. ${ }^{2}$ Alternatively, it has been proposed that humoral and cell-mediated immune responses to Mallory bodies are important in producing the fibrosis which eventually results in cirrhosis. ${ }^{34}$

Mallory bodies (MBs) are clumps of hepatocellular intracytoplasmic eosinophilic, hyaline material. Ultrastructurally, they are composed of filamentous and granular components. ${ }^{5}$ The filaments, which usually form the major physical part of MBs, vary in diameter from 10 to $20 \mathrm{nM}$ and some data suggest that they may be related to intermediate filaments. ${ }^{6}$ The latter filament class is found in the cytoplasm of most cells, including hepatocytes, ${ }^{7}$ and, although their function is not clear, it has been postulated that it is a cytoskeletal one. ${ }^{8}$ Immunological and physicochemical examina-

*Address for correspondence: as above.

Received for publication 25 November 1980 tion of the MBs induced by alcohol in man, and griseofulvin in mice, has shown that MBs contain prekeratin antigens; these antigens are typical of intermediate filaments of epithelial cells. ${ }^{6}{ }^{9}$ Accordingly it has been suggested that MBs result from disruption of prekeratin intermediate filament metabolism in hepatocytes. More recently, however, it has become evident that MBs contain unique antigens $\mathrm{s}^{10}$ and a new intermediate filament antigen which is present in normal liver cells and other epithelial cell types ${ }^{11}$ (Personal observation). The latter antigen is distinct from prekeratin. ${ }^{11}$ It is clear, therefore, that the antigenic structure of MBs is complex.

Although characteristic of alcoholic liver disease, MBs are also found in hepatocytes in other diseases, including primary biliary cirrhosis, Indian childhood cirrhosis, Wilson's disease, and some other hepatic disorders. ${ }^{12}$ The relative proportions of the ultrastructural components of MBs vary in alcoholic liver disease, ${ }^{5}$ but, on light microscopy, MBs in both alcoholic and non-alcoholic liver disease appear identical. In this paper it is shown that MBs in alcoholic and non-alcoholic liver disease are antigenically similar in that they all contain the same unique antigenic determinant. This raises the possibility that the mode of formation of $\mathrm{MBs}$ is 
similar in liver diseases induced by different aetiological agents.

\section{Methods}

Rabbit antiserum to MBs was prepared as previously reported. ${ }^{10}$ Peroxidase labelled swine anti-rabbit IgG was obtained from Dakopatts (Mercia Brocades Ltd., England). Diaminobenzidine and pronase (type V) were obtained from Sigma (England) and trypsin from Difco (UK) and papain from BDH (UK). Liver tissue was obtained by percutaneous needle biopsy and at necropsy. The types of liver disease examined are indicated in Table 4; the diagnoses listed were arrived at on the basis of clinical and morphological data. The tissue was fixed in $10 \%$ buffered formalin ( $\mathrm{pH} \mathrm{7.0)}$ and embedded in paraffin wax by routine methods. $5 \mu \mathrm{M}$ sections were cut and dried on glass slides at $37^{\circ} \mathrm{C}$ for 16 hours, after which enzymatic digestion and detection of MB antigen was carried out as described below.

\section{ENZYMATIC DIGESTION AND DETECTION OF MB ANTIGEN}

Pronase was dissolved in $0.1 \mathrm{M}$ Tris ( $\mathrm{pH} \mathrm{7.5)} \mathrm{im-}$ mediately before use as described by Denk et al. ${ }^{13}$ Papain was dissolved in $0.1 \mathrm{M}$ phosphate buffer (pH 6.5) and stored at $4^{\circ} \mathrm{C}$ for 18 hours after which the solution was filtered, activated with $200 \mathrm{mM}$ cystein, and stored frozen at $-20^{\circ} \mathrm{C}$ until required. Trypsin was dissolved in $0.15 \mathrm{M} \mathrm{NaCl}$ adjusted to $\mathrm{pH} 7.8$ with $1 \mathrm{M} \mathrm{NaOH}$. Each of these enzyme solutions was tested at various concentrations for their ability to unmask the MB antigen in paraffin sections of biopsy and necropsy tissue by immersing sections in the respective enzyme solution for 30 minutes at $37^{\circ} \mathrm{C}$. $\mathrm{MB}$ antigen was localised using a monospecific rabbit antiserum to $\mathrm{MBs}$ by the indirect immunoperoxidase procedure as described earlier. ${ }^{10}$ Controls included substituting MB antiserum with normal rabbit serum, or exposing sections to the second antibody (swine anti-rabbit IgG) only; in a few selected cases the rabbit antiserum to MBs was first absorbed with isolated MBs of $95 \%$ purity ${ }^{10}$ before use in the immunoperoxidase procedure.

\section{Results}

The antiserum used in this study reacts with a determinant which appears to be unique to MBs and reacts with no other tissue component in paraffin sections. ${ }^{10}$ MBs in alcoholic cirrhotic tissue react with this antiserum only when sections have been predigested with proteolytic enzymes
Table 1 Immunohistochemical detection of MBs in an alcoholic cirrhotic liver after various enzyme digestions*

\begin{tabular}{|c|c|}
\hline Enzyme (g/dl) & Immunoreactive $\mathrm{MBS}$ \\
\hline \multicolumn{2}{|l|}{ Papain } \\
\hline$(0 \cdot 1)$ & 0 \\
\hline$(0 \cdot 2)$ & 0 \\
\hline$(0.5)$ & +++ \\
\hline \multicolumn{2}{|l|}{ Pronase } \\
\hline$(0.05)$ & ++ \\
\hline$(0 \cdot 2)$ & $+t+$ \\
\hline$(0.5) \dagger$ & $+++t$ \\
\hline \multicolumn{2}{|l|}{ Trypsin } \\
\hline$(0 \cdot 1)$ & 0 \\
\hline$(0 \cdot 2)$ & ++ \\
\hline$(0 \cdot 5)$ & +++ \\
\hline
\end{tabular}

"Blocks from an alcoholic cirrhotic liver were obtained 24 hours after death, fixed in $10 \%$ buffered formalin, and processed to paraffin wax routinely. Consecutive $5 \mu \mathrm{M}$ sections were digested with trypsin, papain, and pronase (at the concentrations shown) for 30 minutes at $37^{\circ} \mathrm{C}$. MBs were identified by immunohistochemistry (see Methods section) and the number of MBs quantified morphologically on an arbitrary scale from 0 to +++ . This liver contained abundant MBs on routine $H$ and $E$ staining.

tUsing this concentration of pronase, sections fragmented and tended to detach from the slide.

before exposure to the antiserum. As shown in Table 1, immunoreactive MBs are best revealed (unmasked) by predigestion of tissue with $0.2 \%$ pronase, $0.5 \%$ trypsin, or $0.5 \%$ papain for 30 minutes at $37^{\circ} \mathrm{C}$. With the use of papain and trypsin predigested sections from 19 alcoholic cirrhotic livers (obtained at necropsy) it was found that, even using optimum conditions for proteolysis, only nine out of 19 cases treated with trypsin and 17 out of 19 cases treated with papain reacted with antiserum to MBs (Table 2). This could indicate that the determinant recognised by this antiserum was not present in MBs in all cases of alcoholic cirrhosis. This observation, however, could also be due to the length of time each tissue was fixed in formalin. As many of these 19 cases were obtained from the block file of this department and some cases date back to 1962 , it was impossible to accurately check the length of time each block had been fixed in formalin. In view of this a controlled experiment was conducted to explore the effect of fixation on the antigenicity of MBs. As shown in

Table 2 Immunohistochemical detection of MBs in numerous alcoholic cirrhotic livers after enzyme digestion*

\begin{tabular}{lll}
\hline Enzyme (g/dl) & Cases (no.) & $\begin{array}{l}\text { Cases with } \\
\text { immunoreactive MBs (no.) }\end{array}$ \\
\hline Nil & 19 & 0 \\
Papain (0.5) & 19 & 17 \\
Trypsin (0.5) & 19 & 10
\end{tabular}

* Paraffin sections from 19 cases of alcoholic cirrhosis obtained at necropsy (see text) were digested with trypsin and papain before processing for immunohistochemical detection of MBs. Numerous MBs were detectable in all 19 cases by routine $H$ and $E$ staining. 
Table 3 Immunohistochemical detection of $M B s$ in an alcoholic cirrhotic liver as a function of fixation time*

\begin{tabular}{lll}
\hline Fixation time & Enzyme digestion $(\mathrm{g} / \mathrm{dl})$ & Immunoreactive LBs \\
\hline 24 hours & Papain $(0 \cdot 5)$ & +++ \\
& Pronase $(0 \cdot 2)$ & +++ \\
& Trypsin $(0 \cdot 2)$ & +++ \\
14 days & Papain $(0 \cdot 5)$ & ++ \\
& Pronase $(0 \cdot 2)$ & + \\
15 weeks & Trypsin $(0 \cdot 5)$ & 0 \\
& Papain $(0 \cdot 5)$ & + \\
& Pronase $(0 \cdot 2)$ & ND \\
& Trypsin $(0 \cdot 2)$ & 0
\end{tabular}

*Three blocks were taken from an alcoholic cirrhotic liver 24 hours after death; this liver contained numerous $\mathrm{MBs}$ on $\mathrm{H}$ and $\mathrm{E}$ staining. One block was fixed for 24 hours, 14 days, or 15 weeks in $10 \%$ buffered formalin and processed to paraffin wax. Consecutive $5 \mu$ sections from each block were digested with the enzymes shown for 30 minutes at $37^{\circ}$ and processed for immunohistochemical detection of MBs. The number of MBs detected was quantified on an arbitrary scale from 0 to +++

ND: not done.

Table 3 the immunoreactivity of MBs in alcoholic cirrhotic tissue is destroyed by prolonged fixation in $10 \%$ formalin.

The detection of $\mathrm{MBs}$ by routine $\mathrm{H}$ and $\mathrm{E}$ staining and by immunohistochemistry in various forms of alcoholic and non-alcoholic liver disease is shown in Table 4. The biopsies from all cases shown in Table 4 were fixed for 24 hours in $10 \%$ formalin and were digested with $0.5 \%$ trypsin before exposure to antiserum. All 10 normal liver biopsies examined were negative for immunoreactive MBs, but out of 28 cases of alcoholic liver disease 10 contained MBs on both $\mathrm{H}$ and $\mathrm{E}$ and immunohistochemical staining; however, in an additional six cases, immunoreactive MBs were . detected where none was seen on $\mathrm{H}$ and $\mathrm{E}$ staining; in these cases the immunoreactive structures had a granular rather than the classic MB shape (see ref. 10). In primary biliary cirrhosis, Indian childhood cirrhosis, Wilson's disease, diabetes mellitus, and hepatocellular cancer MBs were detected in the same cases by both $\mathrm{H}$ and $\mathrm{E}$ and immunohistochemical staining - that is, five out of 16 cases of primary biliary cirrhosis, all 11 cases of Indian childhood cirrhosis, one out of four cases of Wilson's disease, and the single cases of diabetes mellitus and hepatocellular cancer. All other types of liver disease examined were negative for MBs by $\mathrm{H}$ and E staining and immunohistochemistry.

In Table 5, the 28 cases of alcoholic liver disease are broken down into various pathological categories, and the detection of MBs detected by both $\mathrm{H}$ and $\mathrm{E}$ and immunohistochemical staining compared. In four cases of cirrhosis, with or without alcoholic hepatitis, MBs were detected in all by both methods, whereas, in 12 cases with fatty change only, one contained MBs as revealed by
Table $4 \quad M B$ identification by routine and immunohistochemical methods in various liver diseases*

\begin{tabular}{|c|c|c|c|}
\hline \multirow[t]{2}{*}{ Liver condition } & \multirow[t]{2}{*}{ Cases (no.) } & \multicolumn{2}{|c|}{ Cases with MBs (no.) } \\
\hline & & $H$ and $E$ & $\mathrm{IH}+$ \\
\hline Normal & 10 & $\mathbf{0}$ & $\mathbf{0}$ \\
\hline Alcoholic liver disease & 28 & 10 & 16 \\
\hline Primary biliary cirrhosis (PBC) & 16 & 5 & 5 \\
\hline Indian childhood cirrhosis & 11 & 11 & 11 \\
\hline Wilson's disease & 4 & 1 & 1 \\
\hline Diabetes mellitus & 1 & 1 & 1 \\
\hline$\alpha_{1}$ anti-trypsin deficiency & 2 & 0 & 0 \\
\hline Large duct obstruction & 1 & $\mathbf{0}$ & $\mathbf{0}$ \\
\hline Chronic active hepatitis & 2 & 0 & $\mathbf{0}$ \\
\hline Porphyria & 1 & $\mathbf{0}$ & 0 \\
\hline Polycystic disease & 1 & 0 & 0 \\
\hline Secondary carcinoma & $\hat{i}$ & 0 & $\mathbf{0}$ \\
\hline Primary hepatocellular cancer & 1 & 0 & 0 \\
\hline Ulcerative colitis & 1 & 0 & 0 \\
\hline Hepatocellular carcinomał & 1 & 1 & 1 \\
\hline
\end{tabular}

*MBs were identified by $\mathbf{H}$ and $\mathbf{E}$ staining and immunohistochemistry in consecutive $5 \mu$ sections of liver biopsies from the conditions listed. All biopsies, which were taken for diagnostic purposes, were fixed for 24 hours in $10 \%$ buffered formalin and processed to paraffin wax routinely. Sections were digested with $0.5 \%$ trypsin before immunohistochemical localisation of MBs.

+IH immunohistochemistry.

$¥$ The tumour cells in this case contained abundant MBs as did the adjacent cirrhotic liver. The patient is a female Moslem from the Yemen and does not consume alcohol.

both methods, but another four contained MBs on immunohistochemical testing only. In 12 cases of alcoholic hepatitis, with or without fibrosis, MBs were detected in five by both methods, and in an additional two by the immunohistochemical method alone.

\section{Discussion}

Mallory bodies (MBs) are eosinophilic cytoplasmic masses which are found in the cytoplasm of hepatocytes, and uncommonly in bile ducts, in a variety of liver diseases. In all of these disorders MBs are tinctorially and morphologically similar. MBs in alcoholic liver tissue are composed of two main ultrastructural components-namely, filaments and a granular material..$^{5}$ In Indian childhood cirrhosis, however, it is claimed that MBs are composed mainly of granular material rather than filaments. ${ }^{12}$

Purified MBs from alcoholic liver tissue, ${ }^{13}$ and

Table $5 M B$ identification by routine immunohistochemical methods in various forms of alcoholic liver disease*

\begin{tabular}{lccc}
\hline Liver morphology & Cases (no.) & \multicolumn{2}{c}{ Cases with MBs (no.) } \\
\cline { 2 - 4 } & & H and E & IH \\
\hline Fatty change & 12 & 1 & 5 \\
Acute alcoholic hepatitis & 12 & 5 & 7 \\
Cirrhosis & 4 & 4 & 4 \\
\hline
\end{tabular}

*MBs were detected in biopsies as described in footnote to Table 4. 
from mice fed griseofulvin, ${ }^{7}$ consist of a number of proteins some of which have molecular weights similar to those found in intermediate filaments. MBs in intact tissue react with antibodies to prekeratin (the main protein of epidermal intermediate filaments), so confirming their relationship to this class of cytoplasmic filament. ${ }^{6} \mathrm{MBs}$, however, also contain other antigenic determinants; two are unique $^{1011}$ to MBs, while another is a new intermediate filament antigen which is present in normal hepatocytes and certain other epithelial cells ${ }^{11}$; these three antigens are distinct from prekeratin ${ }^{10} 11$ which cannot be detected in normal hepatocytes. ${ }^{6}$

In view of the ultrastructural, biochemical, and antigenic heterogeneity of MBs the present investigation was performed to determine whether MBs in human liver disorders were antigenically similar or dissimilar. It has been shown here that MBs in alcoholic liver disease, primary biliary cirrhosis, Indian childhood cirrhosis, Wilson's disease, diabetes mellitus, and hepatocellular carcinoma all contain at least one common antigenic determinant. The latter determinant is present on a protein (Mallory body protein), molecular weight 53000 daltons, which was isolated from purified MBs. ${ }^{10}$ Denk et al. ${ }^{6}$ have also reported that the MBs in alcoholic liver disease and those induced in mice by griseofulvin are also antigenically similar in that they react with antibodies to prekeratin. The determinant studied here is distinct from prekeratin. These observations taken together indicate that the mechanism whereby MBs are formed in hepatocytes may be similar in liver diseases induced by dissimilar aetological agents. This mechanism may involve increased synthesis, decreased degradation or secretion, of at least Mallory body protein and prekeratin.

Unfortunately, the other antibodies which react with MBs-namely, anti-prekeratin ${ }^{6}$ and monoclonal antibodies to $\mathrm{MBs}^{11}$ - and recognise determinants distinct from those studied here, can be used only on fresh frozen human liver tissue. ${ }^{611}$ It is possible that a prospective study using all of these antibodies on frozen liver biopsies may reveal antigenic differences in MBs which are characteristic and diagnostic of a particular liver disease.

It is evident that immunohistochemistry is a more sensitive method for detecting MBs and MB related structures than routine staining. Rather surprising was the finding that immunoreactive MB material occurs with greater frequency in fatty livers of alcoholics than was evident from $\mathrm{H}$ and $\mathrm{E}$ sections. It is of interest that the MBs in these fatty livers were not associated with polymorph infiltration or fibrogenesis. Although purified MBs are (directly or indirectly) chemotactic for polymorphs ${ }^{4}$ and induce increased collagen formation by fibroblasts ${ }^{13}$ in vitro the present results indicate that these are not necessarily properties of MBs in vivo. The concept that MB formation is necessary for the progression of acute to chronic alcoholic liver disease ${ }^{4}$ must now be questioned because it is based at least in part on these in vitro experiments. ${ }^{4}{ }^{13}$

K A F was supported by a Wellcome Research Fellowship in Pathology. Professor C W Nayak (University of New Delhi, India), and Dr B C Portman (Liver Unit, Kings College Hospital, London), kindly provided the biopsies from cases of Indian childhood cirrhosis.

\section{References}

${ }^{1}$ Popper, H. The pathogenesis of alcoholic cirrhosis In: Fisher MM, Rankin JG, eds. Alcohol and the liver. New York: Plenum Press, 1977; 289.

${ }^{2}$ van Waes L, Lieber CS. Early perivenular sclerosis in alcoholic fatty liver. Gastroenterology 1977; 73: 646-50. ${ }^{3}$ Zetterman RK, Luisada-Opper A, Leevy CM. Alcoholic hepatitis: cell mediated immunological response to alcoholic hyalin. Gastroenterology 1976; 70: 382-4.

${ }^{4}$ Kanagasundaram N, Kakumu S, Chen T, Leevy CM. Alcoholic hyalin antigen (AHAg) and antibody in alcoholic hepatitis. Gastroenterology 1977; 73: 1368-73.

${ }^{5}$ Yokoo H, Minick DT, Batti F, Kent G. Morphological variants of alcoholic hyalin. Am J Pathol 1972; 69: 25-32.

${ }^{6}$ Denk H, Franke WW, Eckerstorfer R, Schmid E, Kerjaschki D. Formation and evolution of Mallory bodies ('alcoholic hyalin') in murine and human liver revealed by immunofluorescence microscopy with antibodies to prekeratin. Proc Natl Acad Sci USA 1979; 76: 4112-6.

'Franke WW, Schmid E, Kartenbeck J, Mayer D, Hacker H, Bannash P et al. Characterisation of the intermediate sized filaments in liver cells by immunofluorescence and electron microscopy. Biol Cellulaire 1979; 34: 99-110.

${ }^{8}$ Lazarides E. Intermediate filaments: integrators of cellular space. Nature 1980; 283: 249-56.

${ }^{9}$ Franke WW, Schmid E, Osborn M, Weber K. Different intermediate sized filaments distinguished by immunofluorescent microscopy. Proc Nat Acad Sci USA 1978; 75: 5034-8.

${ }^{10}$ Morton JA, Fleming KA, Trowell JM, and McGee JO'D. Mallory bodies-immunohistochemical detection by antisera to unique non-prekeratin components. Gut 1981 .

${ }^{11}$ Morton JA, Bastin J, Fleming KA, McMichael A, Burns J, McGee JO'D. Mallory bodies in alcoholic liver disease: Identification of cytoplasmic filaments/ cell. Gut 1981; 22 : 1-7.

${ }^{12}$ French SW, Sim JS. Franks KE, Burbidge EJ, Denton T, Caldwell MG. Alcoholic hepatitis. In: Fisher MM, Rankin JG, eds. Alcohol and the liver. New York: Plenum Press, 1977; 261.

${ }^{13}$ Chen T, Leevy CM. Collagen biosynthesis in hepatic fibrosis (abstr). Gastroenterology 1973; 64: 178. 